\title{
A Survey on Rural Internet Connectivity in India
}

\author{
Shruthi Koratagere Anantha Kumar, Gangavarapu Vigneswara Ihita, Student Member, IEEE, \\ Sachin Chaudhari, Senior Member, IEEE, Paventhan Arumugam, Senior Member, IEEE
}

\begin{abstract}
Rural connectivity has been a widely researched topic for several years. In India, around $50 \%$ of the population have poor or no connectivity to access digital services. Numerous technological solutions are being tested around the world, as well as in India. The key driving factor for reducing the digital divide is to lower the cost of network deployments and improve service adoption rate by exploring different technological and economical solutions. This survey aims to study rural connectivity and create awareness about the use-cases, state of the art projects and initiatives, challenges, and technologies to improve digital connectivity in rural parts of India. The strengths and weaknesses of different technologies tested for rural connectivity are analysed. The study includes a brief discussion of rural connectivity trials performed in India and around the world. We also explore the rural use-case of the 6G communication system, which would suit the rural Indian scenario.
\end{abstract}

Index Terms-Digital divide, internet connectivity, mobile technologies, 6G,

\section{INTRODUCTION}

Although India has already made the giant leap in the digital revolution, there is still a long way to connect the unconnected. As per a report by the various survey companies based on inputs from the Telecom Regulatory Authority of India (TRAI), there is a national average of $51 \%$ broadband penetration in India versus a mere $29.3 \%$ in rural India, and around $50 \%$ of India's population is connected to the mobile network [1]-[3]. Exacerbated by COVID-19, this digital divide is worsening the existing societal and economic inequalities in the country. Further, there are concerns about widening the connectivity gap due to adopting new digital developments such as ewallets, internet of things (IoT), and artificial intelligence (AI).

The rural communities need to connect to the internet with the help of digital connectivity. Rural areas would benefit from use-cases for digital connectivity, such as personal communication, online banking, e-governance, and smart-farming. But the cost involved in providing connectivity using traditional solutions is very high, lacking economic feasibility to attract investors. The Indian government is undertaking various initiatives to improve connectivity, but still, some challenges require solutions. The solution lies in formulating strategies and initiatives that would consider input from operators, equipment

Shruthi Koratagere Anantha Kumar, is with the StrathSDR Lab, University of Strathclyde, Glasgow, G1 1XQ Scotland, UK (e-mail: k.a.shruthi@strath.ac.uk)

Gangavarapu Vigneswara Ihita and Sachin Chaudhari are with the Signal Processing and Communication Research Centre (SPCRC), International Institute of Information Technology, Hyderabad, 500032, India (e-mail: ihita.g@research.iiit.ac.in, sachin.chaudhari@iiit.ac.in)

Paventhan Arumugam is Director (R\&D) with Education and Research Network (ERNET) India, Indian Institute of Technology, Madras Research Park, Chennai - 600113. e-mail: paventhan@eis.ernet.in) manufacturers, academia, government, and civil societies to understand the requirements of the rural communities to create sustainable solutions for them to leverage for development [4]. Each village would use a different combination of existing technological solutions to improve digital connectivity.

There is extensive research done in solving the digital divide problem around the world for the Indian scenario [1], [4][15]. The research presented in [1], [4]-[7] highlights the different challenges, uses-cases, solutions especially, 5G and justifies the need for innovation in business models for using $5 \mathrm{G}$ technology in the Indian setting with a main focus towards urban areas and its applications. The study in [8] presents the techno-economic feasibility of long term evolution (LTE) in rural India. A study on the role of telecommunication in managing pandemics such as COVID-19 has highlighted the importance of digital connectivity especially, in rural areas [9]. The research [10] explore low cost solutions using TV WhiteSpace (TVWS), whereas in [11] explores an integration of 5G, neutral host networks (NHN), TVWS, and WiFi for providing rural connectivity in India. The need for innovative business models for rural scenarios with MNO and business ecosystem is discussed in [12]. The cost-savings for rural settings are explored by using $5 \mathrm{G}$ network slicing supporting $\mathrm{NHN}$ in the Indian scenario in [13]. Similarly, the study in [14] shows the need for supportive policies for encouraging NHN. The research in [15] discusses the need for supportive spectrum policies for $5 \mathrm{G}$ deployments in rural areas to encourage $6 \mathrm{G}$ deployments with a special focus on the India scenario.

Our research is different from the existing research presented in [1], [4]-[15]. The research in [1], [4]-[6] present a generic study on rural digital connectivity and possible technological with spectrum solutions and business models but without focusing on existing infrastructure or suitability of different technologies in the Indian rural scenario. The study in [7] gives a glimpse of rural connectivity solutions in India only using fibre backhaul, TVWS, and WiFi however lacks a focused study on rural Indian challenges and the suitable solutions. The research in [8]-[13] showcase the use of specific technologies rather than a combination of all the possible technologies of rural connectivity. Our research presents the different technologies to solve the digital divide and assesses their suitability for different use-cases. The study in [14] lacks the study on the suitability of NHN specifically for the rural parts of India. The research in [15] lacks extensive research on the current state of telecommunication in India's scenario.

According to researchers in [16], [17], lack of awareness of appropriate solutions for digital connectivity in India is a significant roadblock. Also, the research performed by [7] 
shows that around $70 \%$ of surveyed institutions didn't know the existence of BharatNet, which is an Indian government initiative to provide fibre connectivity at the Gram Panchayat (GP) level. The key motivation for this survey is to address the lack of awareness among people about the benefits of digital connectivity, technological solutions and applications. This study presents a survey of rural internet connectivity in India. The main contributions in this paper are:

- A discussion on use-case based network design rather than a generic urban style network deployment.

- A survey on the current state-of-the-art initiatives and projects undertaken for rural connectivity in India.

- A discussion on major challenges that need to be addressed to improve rural telecommunication.

- A survey on technological trials for rural areas around the world.

- A case study on different rural trials in the Indian scenario.

- An overview of $6 \mathrm{G}$ solutions for rural connectivity and lessons from the study.

The organisation of the paper is as follows: Section II presents the rural connectivity use-cases for the Indian applications, and the current state-of-the-art initiatives and projects to improve rural connectivity in India. Section III presents the main challenges for reducing the digital divide. Section IV presents a survey of different technologies, their role in solving the issues, strengths and weaknesses of each emerging technology, and the rural trials undertaken around the world, and in India. Furthermore, there is a brief discussion on $6 \mathrm{G}$ solutions, and the learning's focusing on rural connectivity. Finally, Section V presents the conclusion of the study.

\section{RURAL CONNECTIVITY USE-CASES AND STATE-OF-THE-ART INITIATIVES}

The internet provides immense potential for the development of rural communities. The network deployment should consider the possible use-cases for the particular village and design a network accordingly. Unlike in urban scenarios, rural networks are typically loss-making businesses. Hence, the aim of deployment should be to reduce the under-utilisation of resources and to lower the network cost [1], [7], [12], [13]. The network planning should also account for future demands with a realistic view of current demands. The prominent and emerging use-cases for digital connectivity in rural India, as shown in Fig. 1, are explained below:

1) Agriculture: The main occupation of rural communities in India is agriculture. With access to internet connectivity, farmers can use trusted channels to receive the best market price for their commodity and other daily updates for their products to ensure they receive fair returns. The connectivity can improve agricultural productivity by facilitating the sharing of essential information on sowing, crop protection, improving soil fertility and weather, and access to portals such as National Agriculture Market or e-Nam [22], and early-warning systems (EWS). The

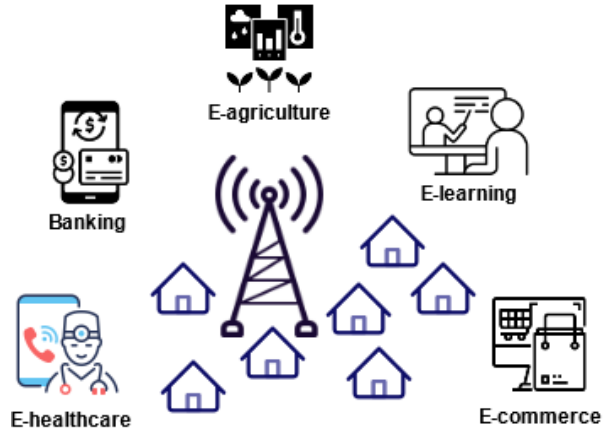

Fig. 1. Rural connectivity use cases

Internet helps farmers manage livestock and enables the improvement of various aspects of livestock production and education.

2) Healthcare: Internet connectivity can help in improving healthcare facilities in rural areas using telehealth services such as long-distance clinical health care, patient and professional health-related education, public health, and health administration. It has been used by emergency medical personnel for consultation during natural disasters and in military battle situations. The various initiatives for rural healthcare that require access to internet connectivity are National Health Portal [23], Pradhan Mantri Surakshit Matritva Abhiyan [24], NHP Directory Services [25], and Indradhanush Immunization [26].

3) Education: Connecting rural communities help enable distance education in remote parts of the country, including vocation training classes to build skill-sets such as teaching, tailoring and weaving [27]. Digitizing and recording teaching material for students with visual impairments is making the education sector even more inclusive. Various initiatives that are accessible using internet connectivity in rural areas are National Mission on Education through Information and Communication Technology (NMEICT) [28], National Digital Library (NDL) [29], SWAYAM Prabha [30], and virtual labs [31]. Professor Raj Reddy Centre on Technology in Service of Society at IIIT Hyderabad has multiple initiatives targeting rural youth education and teacher training [32]. They are also establishing virtual labs to provide remote access to physical labs and research centres.

4) E-governance: Modern-day e-governance requires internet services to access various government aids related to jobs, education, wellness, pension, and justice that are available on the National Government Services Portal [33]. Digital services help in the bill payments, e-registration, storing and accessing the database on the history and approvals for the properties (RERA), pandemics based essential services such as information on the vaccination centre and complaint registrations require access to the internet [1], [18], [34], [35]. Governments also use the internet to increase their outreach, improve understanding of policies, and expand credit 
TABLE I

GOVERNMENT INITIATIVES AND PROJECTS FOR IMPROVING RURAL CONNECTIVITY IN INDIA

\begin{tabular}{|c|c|c|}
\hline Initiative & Pros & Cons \\
\hline Digital India Initiatives & $\begin{array}{l}\text { Aim to connect rural areas with high-speed internet networks and } \\
\text { improve digital literacy via stable and secure digital infrastructure [18] }\end{array}$ & $\begin{array}{l}\text { Last mile connectivity depends on } \\
\text { the operators, and requires newer } \\
\text { business models }\end{array}$ \\
\hline State Wide Area Network (SWAN) & $\begin{array}{l}\text { Solves the connectivity problem from the State HQ up to the Block } \\
\text { level [19] }\end{array}$ & $\begin{array}{l}\text { Still the last mile issue in connect- } \\
\text { ing the village remains }\end{array}$ \\
\hline $\begin{array}{l}\text { BharatNet or Bharat Broadband } \\
\text { Network Limited (BBNL) }\end{array}$ & $\begin{array}{l}\text { create a robust middle-mile infrastructure using optical fibre for } \\
\text { reaching broadband connectivity to all GPs in India [20]. As per the } \\
\text { project, there are } 1,65,082 \text { GPs to which optical fibre cable has been } \\
\text { connected and necessary equipment are installed [20]. }\end{array}$ & $\begin{array}{l}\text { Last mile connectivity depends on } \\
\text { the operators, and techno-economic } \\
\text { feasibility }\end{array}$ \\
\hline $\begin{array}{l}\text { PM-WANI (Wi-Fi Access Network } \\
\text { Interface) scheme }\end{array}$ & $\begin{array}{l}\text { A decentralized system of public access points to increase internet } \\
\text { connectivity and address last-mile connectivity at cheap rates. There } \\
\text { is no license, no registration, and no fee required for the Public Data } \\
\text { Offices (PDOs), which could be small shops or even Common Service } \\
\text { Centres as access points [21]. }\end{array}$ & $\begin{array}{l}\text { Lacks collaboration with MNOs, } \\
\text { WiFi-based network leads to diffi- } \\
\text { culty in roaming for mobile rural } \\
\text { customers of the PM-WANI net- } \\
\text { work. }\end{array}$ \\
\hline
\end{tabular}

penetration.

5) Banking: Reliant and secure digital connectivity can strengthen rural access to financial services enabling them to find appropriate insurance, loans, support to manage and mitigate risk. It will assist with better farmer profiling systems for agricultural credit decisions and protection for farmers in times of bad weather or disaster. The digital initiatives and payments that often require good internet connectivity such as the National Bank for Agriculture and Rural Development (NABARD) [36], Pradhan Mantri Jan Dhan Yojana [37], the Government of India scheme, Kisan Credit Card (KCC), e-wallets, UPI (united payment interface) and BHIM.

6) E-commerce: With connectivity comes access to regional and global markets. E-commerce opportunities have been crucial in purchasing and selling agro-based products and handicrafts. Rural communities have a digital platform to showcase diverse cultures and crafts promoting tourism, such as GeM. Handicrafts and paintings from India, such as Kalamkari paintings, Lepakshi handicrafts, and Kondapalli toys, can be displayed and sold in international markets via e-commerce platforms when connected to the internet.

By considering the above mentioned emerging rural usecases and already existing ones, the government of India is trying to address the issues of rural internet penetration. Table I shows the different projects and initiatives such as Digital India, SWAN, BharatNet, and PM-WANI [4], [7], [18]-[20] undertaken by the government of India. Many studies highlight the need for subsidy or support for rural connectivity [7], [14], [15], [38]. The rural markets need a push to become selfsufficient and profitable in the long run. These initiatives are going to help rural communities set up their networks based on their use cases.

\section{Challenges SPecific to Indian Setting}

Though the government is encouraging initiatives and projects to improve rural connectivity focusing on middle-mile connectivity, there still exist challenges in improving last-mile connectivity and expanding the network with the operators [1], [7], [8], [13], [17], [39], [40]. Hence, the key challenges that need to be addressed by the operators are:

1) Population distribution and topography: The population of villages in rural parts of India can vary from as low as 100 to more than 10,000 people per village [64]. Furthermore, India has diverse topography such as the plane, plateau, mountain and desserts and extreme climatic conditions. A sparsely populated village has the lowest priority while deploying networks because of low return on investment. An uneven terrain poses a challenge in providing digital connectivity [7], [13], [65].

2) Cost: The main factor which makes rural connectivity difficult is the cost of providing internet solutions in rural areas [1], [13], [41], [57], [66]. The deployment cost is high due to various factors such as the nonexistence of either backhaul or point of presence (PoP), cost of equipment, repair and maintenance, and spectrum licensing in hard-to-reach locations. The technoeconomic study of different technologies highlight the need for reduced deployment and operational costs along with newer business models in rural areas for improving rural connectivity, [1], [7], [8], [13], [41], [43], [67][69].

3) Per-capita income: The pricing should be attractive for people living in rural areas to spend on digital applications due to lower per-capita incomes [1], [3], [7], [13], [64]. Newer revenue models to attract rural areas customers to enrol for internet services is required. The local businesses should also be encouraged to use facilities offered by internet services, and enlightened with the benefits from being online.

4) Business models: The lack of innovative business models is the major challenge for rural connectivity [3], [7], [8], [70]. The traditional business models used for urban scenarios are not suitable for rural scenarios as those focus on high ARPU, high customer base, and long investment duration [5]. The new business model needs to focus on factors such as low ARPU, low to 
TABLE II

COMPARISON OF DIFFERENT RURAL CONNECTIVITY SOLUTIONS

\begin{tabular}{|c|c|c|c|}
\hline Technology & References & Strengths & Weaknesses \\
\hline $5 \mathrm{G}$ & $\begin{array}{l}\text { [12], [13], [35], } \\
{[41]-[44]}\end{array}$ & $\begin{array}{l}\text { Very high speed, versatile applications, reasonable } \\
\text { pricing plans, remote maintenance, software defined } \\
\text { networking, shared spectrum, supports multiple fre- } \\
\text { quencies, NHN, supports mobility up to } 500 \mathrm{kmph} \text {, } \\
\text { energy efficient }\end{array}$ & $\begin{array}{l}\text { High TCO, difficulty obtaining spectrum licence, } \\
\text { higher bandwidth, significant network upgrade costs, } \\
\text { requires legal approvals and network planning, rev- } \\
\text { enue depends on the subscription rates }\end{array}$ \\
\hline Network slicing & $\begin{array}{l}{[12]-[14],[45]-} \\
{[50]}\end{array}$ & $\begin{array}{l}\text { Easily scalable, low cost, supports neutral hosts and } \\
\text { spectrum sharing, resource allocation as per demand, } \\
\text { isolation of slices, } 5 \mathrm{G} \text { features, easy setup }\end{array}$ & $\begin{array}{l}\text { Technology implementation, legal and government } \\
\text { approvals, spectrum regulations }\end{array}$ \\
\hline Satellite internet & [7], [51]-[53] & $\begin{array}{l}\text { Provide coverage anywhere on the earth, high speed } \\
\text { data rates, easy setup, supports OTT, smooth han- } \\
\text { dover for mobile devices, low latency }\end{array}$ & $\begin{array}{l}\text { High subscription fees, customer premise equipment } \\
\text { (CPE), higher cost, dependent on weather, no roam- } \\
\text { ing for in-house antenna, lower data capacity limits } \\
\text { compared to terrestrial networks }\end{array}$ \\
\hline $\begin{array}{l}\text { Hot air balloon/ } \\
\text { UAV / Drone }\end{array}$ & [7], [54]-[56] & $\begin{array}{l}\text { Wireless infrastructure, long distance coverage, rela- } \\
\text { tively easy to setup anywhere, low requirements for } \\
\text { base station }\end{array}$ & $\begin{array}{l}\text { Techno-economic feasibility is not fully studied, } \\
\text { weather related challenges, legal approvals, inter- } \\
\text { ference planning, fuel issues, roaming agreements, } \\
\text { continuous service requirement is not feasible }\end{array}$ \\
\hline TVWS & {$[10],[57]-[61]$} & $\begin{array}{l}\text { Very good coverage, supports LTE, 5G small cells } \\
\text { and internet, long distance transmission, wireless } \\
\text { backhaul, long transmission ranges, lower cost }\end{array}$ & $\begin{array}{l}\text { Spectrum licence, dynamic spectrum sharing (DSA) } \\
\text { technology, licence duration, middle-mile technol- } \\
\text { ogy, user-devices do not operate on these bands, } \\
\text { power restrictions, interference management, dy- } \\
\text { namic change in frequency of operation }\end{array}$ \\
\hline WiFi long range & {$[62],[63]$} & $\begin{array}{l}\text { Easy to setup, unlicensed bands, devices support } \\
\text { WiFi bands, plug and play devices, in-house or local } \\
\text { areas networks, very high data rates }\end{array}$ & $\begin{array}{l}\text { Limited power supply, interference prone, cus- } \\
\text { tomised for rural requirements, handover for mobile } \\
\text { networks, lower coverage regions compared to li- } \\
\text { censed technologies }\end{array}$ \\
\hline
\end{tabular}

the moderate customer base, low network take up and moderate investment duration [71].

5) Funding and investment: The MNOs and ISPs obtain funding and investment from financial institutions or government agencies [1]. As the rural telecommunication business is non-profitable for a new entrant or infrastructure providers ( $\mathrm{InP}$ ), the lack of funding and subsidies allocated for rural last-mile connectivity and its development is another roadblock [7]. There is a need for innovations in the possible funding model for local operators in rural areas.

6) Technology: Mobile communication technology needs to be modified for meeting the rural communities' requirements. The requirements of rural networks are high coverage (up to $10 \mathrm{~km}$ radius), high data rates (100 Mbps or more), high energy efficiency, high spectral efficiency, support all use-cases using single network and soft handover [1], [3], [7], [13], [34], [72]. There is also a need for local spectrum licensing to encourage micro-operators or InP [12], [13], [73]. Open network technologies such as OpenRAN, 5G open-source base stations, and other open source technologies could significantly reduce the cost of deployments [74].

7) Electricity: The rural areas in India have irregular or unreliable power supply issues [7], [8], [60], [65], [75]. The rural telecommunication system stresses the need for renewable energy sources and a highly power-efficient system. The $5 \mathrm{G}$ systems are $10 \mathrm{x}$ times more powerefficient than of $4 \mathrm{G}$ systems which is an advantage for rural areas.

8) Digital awareness: Another challenge is digital aware- ness among rural users. People need to understand the benefits and comfort offered by digital solutions, and then they would demand better services [1], [65], [76]. Since India is a multi-lingual country, the content should be available in different languages to attract rural subscribers on the network [77], [78].

\section{Possible technologicAl SOLUTIONS FOR INDiAN SETTINGS}

Technologies such as $3 \mathrm{G}$ and $4 \mathrm{G}$ are operational in rural areas [8], these technologies are expensive to cater to rural conditions. Furthermore, they support passive sharing that does not reduce the cost as significantly as active sharing using 5G and open networks [79]. Technologies shown in Fig. 2 such as $5 \mathrm{G}$, hot air balloon base stations, drone base stations, satellite internet and backhaul, long-range WiFi networks, unmanned aerial vehicle (UAV), and TVWS, were tested as rural solutions. The scope of this research lies in exploring different technologies and understanding their suitability for different rural scenarios. The research in [70] presents different rural technologies with their viability in terms of network architecture, performance, key characteristics, and deployment concerns.

In Table II summarises various rural technologies and their strengths along with weaknesses. The challenges with 5G networks for rural solutions are local spectrum licensing, ease of new entrants in local markets, subscription of services, the performance of network slicing and adoption rate. Furthermore, in [7], [60], [68], the importance of renewable energy for rural connectivity was investigated, with the issue of connection to an alternate energy source in the absence of 


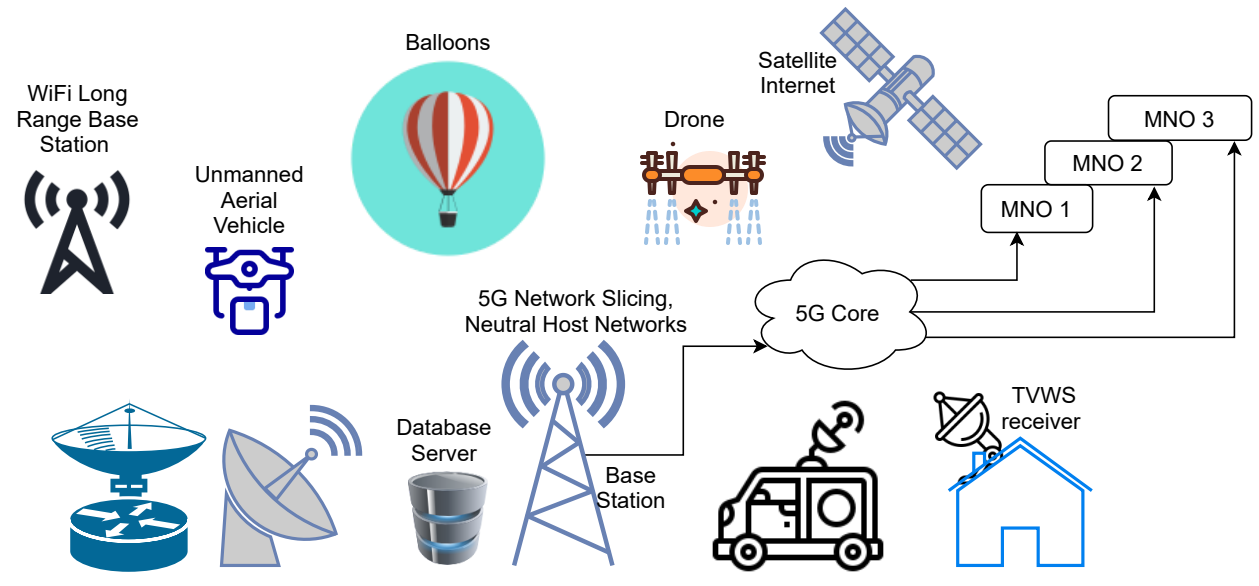

Fig. 2. Different rural technologies for last mile connectivity

renewable sources. Similarly, though TVWS communication has a long-range, parameter limits exist for deployment in terms of factors such as power levels, maximum allowable interference levels and spectrum licensing [7], [10], [60], [68]. According to a study in [7], [68], there is a need to research scalability and business model for technologies such as hot air balloon base stations, drone base stations, satellite backhaul, long-range $\mathrm{WiFi}$, and UAV. These solutions in their current state are not yet totally appropriate for use in rural areas at the current stage for a long-term wide-area network as there is a lack of techno-economic feasibility study, and reliability analysis.

Table II highlights that one solution is not going to fix the whole rural connectivity. A combination of these technologies is going to cater to the rural use-cases needs. These studies highlight the importance of interoperability and loose coupling between various technologies to support the smooth handover of mobile users. Hence, this fuels the need for standardising technologies to channel interaction between technologies and lower the cost.

\section{A. Rural trials around the world}

1) $5 G: 5 G$ is the fifth generation of communication systems supporting three major use-cases such as enhanced mobile broadband (eMBB), ultra-low latency communications (uRLLCs), and massive machine to machine communications (mMTC). To address the issue of rural internet connectivity, researchers began testing the suitability of the design of a 5G communication infrastructure to address the needs of rural use-cases. In [41], [80], [81], the research on deploying and operating a nationwide $5 \mathrm{G}$ network with a duration 10 years was investigated. It was concluded that policy and technological advancement along with smart innovations in rural telecommunication business models will drive the connectivity.

2) Network slicing: Network slicing is one of the $5 G$ architectures that support the usage of virtual networks to increase resource utilisation [45]. It is investigated extensively for rural solutions, ranging from slicing in the radio access network to end-to-end network sharing. The network slicing for broadband-related applications is explored in [35] to improve rural broadband services for eMBB services. The research shows the discussions on bridging the digital divide issues and focusing on multi-tenancy sharing of infrastructure to make rural connectivity sustainable. In [43], the authors advocated using a single slice to give basic but free internet connectivity to people who cannot afford it in the Democratic Republic of Congo (DRC), while the rest slices are for commercial operations. The solution educates rural residents about the advantages of having access to the internet. The idea of employing 5G NHN for vertical industries, tested in a pilot study on the Orkney Islands, United Kingdom, where one slice is for BBC [38] broadcasting applications and other slices for rural industrial verticals. The learning's from the trial is that $5 \mathrm{G}$ network slicing is an innovative option to encourage rural connectivity.

3) Satellite internet: In hard-to-reach rural areas and other topography areas, low earth orbit satellites provide internet connectivity, [52], [82]. Today, various satellite telecommunication companies such as OneWeb, SpaceX, Eutelsat, and Blue Origin are launching satellites to provide $5 \mathrm{G}$ and internet services for different applications [51], [53], [83]. The pricing would vary depending upon the application served. OneWeb and SpaceX aim to remove the dependency of rural areas on fibre backhaul by providing excellent coverage and data rates using satellite internet. They would offer attractive pricing plans for rural inhabitants.

4) Hot air balloon/UAV/Drone: The flying antenna system between the backhaul network and the access network works as a base station in the air. The research in [7], [54], [55], [84] shows the application of hot air balloons/UAV/Drone for digital connectivity in hard-to-reach areas due to topographical challenges and emergency services. The cost of the network is highly dependent on the number of drones required to support the use-cases. The results were satisfactory in the test trials. Companies such as Google, Facebook, Amazon, Taara and 
Walmart are researching the use of these technologies for $5 \mathrm{G}$ service provisioning [56], [85].

5) TVWS: TVWS is a telecommunication technology in which information is transmitted using the TV frequency bands. After the digitisation of the TV channels, a swathe of frequency became available around the world. In [10], [57], [58], [60], the authors study the network by using TVWS technology to provide long distance wireless backhaul capacity. 2G, 3G, 4G, 5G or unlicensed spectrum technologies for operations on end-user devices while TVWS acts as a backhaul/midhaul technology. The frequency bands available for usage varies in different countries around the world.

6) WiFi long range: Long-range $\mathrm{WiFi}$ is the technology that uses $\mathrm{WiFi}$ for long-distance wide-area communication. The recent study in IEEE 802.11ah shows that it has a potential for long-range backhaul and long outdoor network [86] with power restrictions. This technology trials were performed as well as tested by different researchers [7], [59], [62], [87]. It is operating in unlicensed spectrum bands [88]. This technology also uses MIMO systems to provide long-range coverage in rural areas and adhere to the usage policy of unlicensed spectrum bands.

\section{B. Overview of rural trials in the Indian scenario}

The research in [89] shows the need for sustainable internet business models and possible technologies. The rural network will only become sustainable when the business model suits the demand and capacity available for that village. The suitability and challenges of using long-range $\mathrm{WiFi}, 2 \mathrm{G} / 3 \mathrm{G}$, LTE, and a few other technologies have been discussed in [90]. The research shows that WiFi involves lower cost and easy setup but is prone to interference, whereas LTE is suitable to support roaming for rural customers though it is expensive. The trial [91] shows the 'DakNet' with long-range WiFi to connect rural parts of India. The author highlights the need for cheaper CAPEX costs and low spectrum licensing costs. The researchers in [87] show the usage of long-range WiFi with a multi-hop mesh network for affordable connectivity for fishermen. The network provides coverage up to $100 \mathrm{~km}$ using multi-hop network concepts. In [11], the authors discuss the technology and architecture related to 5G IEEE standard network slicing for rural connectivity using WiFi as the lastmile network. All these researchers show the use of WiFi routers in the village for end-users to access the internet. There is a need to make mobile technologies easily accessible and available to increase mobile services' uptake. The report [92] shows the TVWS trials for connecting schools in rural parts of Srikakulam, Andhra Pradesh, India. Meanwhile, the reports [56], [93] describe the Free Space Optical Communication (FSOC) Technology trials performed for providing connectivity in hard-to-reach places in Kohima, Nagaland by ERNET.

\section{C. $6 G$ - integration of different technologies}

The latest generation of telecommunication systems researched is $6 \mathrm{G}$, which supports Tetra-Hertz frequency band communication and a minimum data speed of $1 \mathrm{Gpbs}$ speed per user. The research in [7], [68], [69] presents a survey on delivering $6 \mathrm{G}$ connectivity in rural areas, challenges, different technologies and viable solutions. Several research groups are working on $6 \mathrm{G}$ research ideas to tackle digital divide issues. The $6 \mathrm{G}$ includes rural connectivity as one of the main usecases [7]. Table III shows a brief comparison of 5G and $6 \mathrm{G}$ communication systems. The key rural connectivity aims of 6G as stated in [6], [7], [15], [68], [79] are as summarised below:

- Low-cost rural connectivity technology, backhaul solutions to reduce the overall cost, remote monitoring and maintenance of the network.

- Efficient spectrum usage in the spectrum sharing bands, energy consumption to address unreliable energy supply, resource allocation to support multiple applications as well as utilisation. The network supports guaranteed QoS and high reliability to encourage MNO investments for the rural connectivity ecosystem.

- Smart infrastructure for telecommunication services in rural areas.

TABLE III

5G AND 6G COMPARISON

\begin{tabular}{|c|c|c|}
\hline Parameter & $5 G$ & 6G \\
\hline $\begin{array}{l}\text { Maximum fre- } \\
\text { quency }\end{array}$ & $90 \mathrm{GHz}$ & $10 \mathrm{THz}$ \\
\hline Technologies & $\begin{array}{l}\text { mmWave, IoT, } \\
\text { industry } 4.0, \\
\text { network slicing, } \\
\text { massive MIMO }\end{array}$ & $\begin{array}{l}\text { Satellite integration, THz, } \\
\text { autonomous vehicles, hap- } \\
\text { tics communications, in- } \\
\text { telligent surfaces }\end{array}$ \\
\hline $\begin{array}{l}\text { End-to-end } \\
\text { latency }\end{array}$ & $10 \mathrm{~ms}$ & $1 \mathrm{~ms}$ \\
\hline Data speeds & $1 \mathrm{Gbps}$ & 1 Tbps \\
\hline
\end{tabular}

6G and older technologies would co-exist and require smooth interoperability between these technologies. The $6 \mathrm{G}$ rural connectivity solutions would encourage the business for micro-operators or InP, the MNOs, and an internet service provider (ISP), can lease services from the InP in rural areas providing services to their end-customers. The demand and supply should be proportional to keep the cost reasonable. The proposed research ideas include use-cases for various stakeholders such as standardisation bodies, national and international regulations, equipment manufacturers, MNOs, ISP, schools, hospitals, councils, indoor-building service providers, satellite service providers, vehicular connectivity providers and hospitals. India could also benefit from $6 \mathrm{G}$ rural solutions.

\section{CONCLUSION}

This research paper provides a survey on rural connectivity challenges and possible solutions in India. Connecting more than $50 \%$ of India's population, most of whom live in rural areas, to high-speed internet is a serious issue to solve. Thus, this paper provides awareness of the use-cases, the government initiatives and projects, challenges, and technologies available for rural connectivity in the Indian scenario. The technological solutions and their strengths, as well as weaknesses, are 
discussed. There is a need to weigh the challenges, initiatives, and technologies to find a solution that caters to the rural usecases and demand. The lesson learnt from the survey is that no single solution is suitable for all villages. For rural connectivity improvement, there is a need for a combination of technologies and smooth interoperability between technologies. Finally, this paper presents an overview of possible rural solutions using 6G technologies that would co-exist with other technologies. A good understanding of the demand and the most feasible technologies to provide connectivity in the village using the appropriate initiatives would help deploy and operate a technoeconomically viable network in rural areas.

\section{REFERENCES}

[1] TRAI releases White Paper on 'Enabling 5G in India' - Telecom Regulatory Authority of India. [Online]. Available: https://trai.gov.in/notifications/press-release/trai-releases-whitepaper-enabling-5g-india

[2] R. Prasad and V. Sridhar, "Allocative efficiency of the mobile industry in India and its implications for spectrum policy," Telecommunications Policy, vol. 33, no. 9, pp. 521-533, 2009.

[3] Rural subscriber figure report - cellular operators association of India. [Online]. Available: https://coai.com/statistics/rural-subscriberfigure-report

[4] (2020) 5G India: Department of telecommunications, ministry of communication, government of India. [Online]. Available: https://dot.gov.in/5g-india-2020

[5] Can wireless technology alone blur the digital divide? - IEEE communications society. [Online]. Available: https://www.comsoc.org/publications/ctn/can-wireless-technologyalone-blur-digital-divide

[6] S. Harri and et al., "6G white paper on connectivity for remote areas," 6G Resesarch vision, vol. 5, 2020.

[7] E. Yaacoub and M.-S. Alouini, "A key $6 \mathrm{~g}$ challenge and opportunity-connecting the base of the pyramid: A survey on rural connectivity," Proceedings of the IEEE, vol. 108, no. 4, pp. 533-582, 2020.

[8] A. Jha and D. Saha, "Techno-economic assessment of the potential for LTE based 4G mobile services in rural India," in International Conference on Advanced Networks and Telecommunications Systems (ANTS). IEEE, 2015, pp. 1-6.

[9] A. Jhunjhunwala, "Role of telecom network to manage Covid-19 in India: Aarogya setu," Transactions of the Indian National Academy of Engineering, vol. 5, pp. 157-161, 2020.

[10] A. Singh, K. K. Naik, and more, "UHF TVWS operation in Indian scenario utilizing wireless regional area network for rural broadband access," International Conference on Next Generation Intelligent Systems (ICNGIS), pp. 1-6, 2016.

[11] M. Khaturia, P. Jha, and A. Karandikar, "Connecting the unconnected: Toward Frugal 5G network architecture and standardization," IEEE Communications Standards Magazine, vol. 4, no. 2, pp. 64-71, 2020.

[12] K. A. Shruthi and et al., "Business model for rural connectivity using multi-tenancy 5G network slicing," in IEEE 17th International Conference on Smart Communities: Improving Quality of Life Using ICT, IoT and AI (HONET), 2020, pp. 182-188.

[13] Shruthi and et al., "Techno-economic study of 5G network slicing to improve rural connectivity in India," 2021, accepted by IEEE Open Journal of the Communication Society.

[14] J. Lähteenmäki, "The evolution paths of neutral host businesses: Antecedents, strategies, and business models," Telecommunications Policy, vol. 45 , no. 10, p. 102201, 2021

[15] E. J. Oughton and et al., "Supportive 5G infrastructure policies are essential for universal 6G: Assessment using an open-source technoeconomic simulation model utilizing remote sensing," IEEE Access, vol. 9, pp. 101924-101945, 2021.

[16] A. Jain, "Digital india-targeting overall growth: A critical analysis," Advance and Innovative Research, p. 343, 2019.

[17] Indian Institute of Technology Bombay.(Jul. 2016).Planning for BharatNet Phase 2. [Online]. Available: http://grammarg.in/wpcontent/uploads/2018/09/2.pd
[18] Digital India Programme. [Online]. Available: https://www.digitalindia.gov.in/infrastructure

[19] (2021) State wide area network (swan). [Online]. Available: https://www.meity.gov.in/content/state-wide-area-network-swan

[20] Bharat Net. [Online]. Available: http://bbnl.nic.in/

[21] The PM-WANI Scheme: An explain. [Online]. Available: https://internetfreedom.in/pm-wani-explainer/

[22] National agriculture market. [Online]. Available: https://www.enam.gov.in/web/

[23] National health portal. [Online]. Available: https://www.nhp.gov.in/

[24] Pradhan mantri surakshit matritva abhiyan. [Online]. Available: https://pmsma.nhp.gov.in/

[25] NHP health: Directory services mobile application. [Online] Available: https://www.nhp.gov.in/nhp-health-directory-services-mobileapplication

[26] Mission Indradhanush. [Online]. Available: https://www.nhp.gov.in/mission-indradhanush1

[27] K. M. Devi and et al., "Empowering IT education in rural India," in 12th International Conference on Information Technology Based Higher Education and Training. IEEE, 2013, pp. 1-4.

[28] National mission on education through information and communication technology. [Online]. Available: http://www.nmeict.ac.in/

[29] National digital library. [Online]. Available: https://ndl.iitkgp.ac.in/

[30] Swayam prabha. [Online]. Available: https://www.swayamprabha.gov.in/

[31] Virtual labs. [Online]. Available: https://www.vlab.co.in/

[32] Raj Reddy Center on Technology in Service of Society. [Online]. Available: https://prrrc.iiit.ac.in/

[33] National government services portal. [Online]. Available: https://services.india.gov.in/

[34] T. Norp, "5G requirements and key performance indicators," Journal of ICT Standardization, vol. 6, no. 1, pp. 15-30, 2018.

[35] P. P. Latapu and et al., "Bridging the digital divide in Tonga through a sustainable multi-tenancy broadband infrastructure: Are we ready?" in International Conference on Environmental Engineering (EE). IEEE, 2018, pp. 1-6.

[36] National Bank for Agriculture and RuralDevelopment(NABARD). [Online]. Available: https://www.nabard.org/

[37] Pradhan Mantri Jan Dhan Yojana. [Online]. Available: https://pmjdy.gov.in/

[38] (2019) 5G RuralFirst: Project conclusion report. [Online]. Available: https://www.5gruralfirst.org/project-conclusion-report/

[39] Your phone is dead in nearly 28,000 villages of India. [Online]. Available: https://www.financialexpress.com/industry/your-phone-isdead-in-nearly-28000-villages-of-india-these-reasons-to-blame-for-nomobile-network/1875037/

[40] How COVID-19 deepens the digital education divide in India. [Online]. Available: https://www.weforum.org/agenda/2020/10/howcovid-19-deepens-the-digital-education-divide-in-india/

[41] E. J. Oughton and Z. Frias, "The cost, coverage and rollout implications of 5G infrastructure in Britain," Telecommunications Policy, vol. 42, no. 8 , pp. 636-652, 2018

[42] A. Al-Dulaimi, X. Wang, and I. Chih-Lin, $5 G$ networks: Fundamental requirements, enabling technologies, and operations management. John Wiley \& Sons, 2018.

[43] J. Noll, S. Dixit, and et al., "5G network slicing for digital inclusion," in 10th International Conference on Communication Systems \& Networks (COMSNETS). IEEE, 2018, pp. 191-197.

[44] J. Markendahl and A. Ghanbari, "Shared smallcell networks multioperator or third party solutions-or both?" in 11th International symposium and workshops on modeling and optimization in mobile, Ad Hoc and wireless networks (WiOpt). IEEE, 2013, pp. 41-48.

[45] A. Ghosh, A. Maeder, M. Baker, and D. Chandramouli, " $5 \mathrm{G}$ evolution: A view on $5 \mathrm{G}$ cellular technology beyond 3GPP release 15," IEEE Access, vol. 7, pp. 127 639-127651, 2019.

[46] M. Cosovic, A. Tsitsimelis, D. Vukobratovic, J. Matamoros, and C. Anton-Haro, "5G mobile cellular networks: Enabling distributed state estimation for smart grids," IEEE Communications Magazine, vol. 55, no. 10, pp. 62-69, 2017.

[47] J. S. a. a. Walia, "5G micro-operators for the future campus: A technoeconomic study," in Internet of Things Business Models, Users, and Networks. IEEE, 2017, pp. 1-8.

[48] J. S. Walia and et al., "Future scenarios and value network configurations for industrial 5G," in 8th International Conference on the Network of the Future (NOF). IEEE, 2017, pp. 79-84. 
[49] P. Rost, M. Breitbach, and et al., "Customized industrial networks: Network slicing trial at Hamburg seaport," IEEE Wireless Communications, vol. 25, no. 5, pp. 48-55, 2018.

[50] N. Haddaji, K. Nguyen, and M. Cheriet, "TCO planning game for 5G multitenant virtualized mobile backhaul (v-mbh) network," Journal of Lightwave Technology, vol. 37, no. 24, pp. 6193-6206, 2019.

[51] M. Giordani and M. Zorzi, "Satellite communication at millimeter waves: A key enabler of the 6G era," in International Conference on Computing, Networking and Communications (ICNC). IEEE, 2020, pp. 383-388.

[52] Can new satellite constellations bridge the digital divide? [Online]. Available: https://www.smartcitiesworld.net/opinions/opinions/can-newsatellite-constellations-bridge-the-digital-divide

[53] G. Giambene, S. Kota, and P. Pillai, "Satellite-5G integration: A network perspective," IEEE Network, vol. 32, no. 5, pp. 25-31, 2018.

[54] P. Sudheesh and et al., "Sum-rate analysis for high altitude platform (HAP) drones with tethered balloon relay," IEEE Communications Letters, vol. 22, no. 6, pp. 1240-1243, 2017.

[55] M. Hunukumbure and G. Tsoukaneri, "Cost analysis for drone based $5 \mathrm{G}$ eMBB provision to emergency services," in Globecom Workshops. IEEE, 2019, pp. 1-5.

[56] Taara. [Online]. Available: https://x.company/projects/taara/

[57] M. Deshmukh and et al., "Wireless broadband network on TVWS for rural areas: An Indian perspective," in 16th International Symposium on Wireless Personal Multimedia Communications (WPMC). IEEE, 2013 pp. 1-5.

[58] M. Khalil and et al., "Feasibility, architecture and cost considerations of using TVWS for rural internet access in 5G," in 20th Conference on Innovations in Clouds, Internet and Networks. IEEE, 2017, pp. 23-30.

[59] D. Anderson, K. Shruthi, and et al., "Evolving Spectrum Sharing Methods, Standards and Trials: TVWS, CBRS, MulteFire and More," Spectrum Sharing: The Next Frontier in Wireless Networks, pp. 59-74, 2020.

[60] C. McGuire and et al., "Enabling rural broadband via TV white space," in 5th International Symposium on Communications, Control and Signal Processing. IEEE, 2012, pp. 1-4.

[61] Connected nations 2020 - ofcom. [Online]. Available: https://www.ofcom.org.uk/research-and-data/multi-sectorresearch/infrastructure-research/connected-nations-2020

[62] J. Lun and et al., "5G New Radio for rural broadband: How to achieve long-range coverage on the $3.5 \mathrm{GHz}$ band," IEEE Vehicular Technology Conference, 2019.

[63] R. D. Singh, "Wireless for communities: Empowering communities through wireless connectivity," IEEE Internet Computing, vol. 16, no. 03, pp. 77-79, may 2012.

[64] India: monthly ARPU for wireless services 2020. [Online]. Available: https://www.statista.com/statistics/915436/india-monthly-arpu-forgsm-and-lte-services/

[65] GSMA - closing the coverage gap: How innovation can drive rural connectivity - mobile for development. [Online]. Available: https://www.gsma.com/mobilefordevelopment/resources/closingthe-coverage-gap-how-innovation-can-drive-rural-connectivity/

[66] C. Ovando, J. Pérez, and A. Moral, "Lte techno-economic assessment: The case of rural areas in spain," Telecommunications Policy, vol. 39, no. 3-4, pp. 269-283, 2015.

[67] S. Friedner and R. House, "5G infrastructure requirements in the UK," LS telcom UK, Tech. Rep, 2016.

[68] W. Jiang and et al., "The road towards 6G: A comprehensive survey," IEEE Open Journal of the Communications Society, vol. 2, pp. 334-366, 2021.

[69] A. Shahraki and et al., "A comprehensive survey on 6G networks: Applications, core services, enabling technologies, and future challenges," arXiv preprint arXiv:2101.12475, 2021.

[70] M. Khalil and et al., "A comparative study of rural networking solutions for global internet access," in International Conference on Information Science and Communication Technology (ICISCT). IEEE, 2019, pp. $1-5$.

[71] World internet users statistics and 2020 world population stats. [Online]. Available: https://www.internetworldstats.com/stats.htm

[72] J. Benseny and H. Hämmäinen, "Value network analysis in a lowcost and affordable internet," in European Conference on Networks and Communications, 2016, pp. 148-152.

[73] T. Sanguanpuak and et al., "Network slicing with mobile edge computing for micro-operator networks in beyond 5G," in 21st International
Symposium on Wireless Personal Multimedia Communications (WPMC). IEEE, 2018, pp. 352-357.

[74] I. Chih-Lin and et al., "5G: rethink mobile communications for 2020," Philosophical Transactions of the Royal Society A: Mathematical, Physical and Engineering Sciences, vol. 374, no. 2062, p. 20140432, 2016.

[75] J. Cross, "No current: Electricity and disconnection in rural india," in Electrifying Anthropology. Routledge, 2020, pp. 64-81.

[76] GSMA - infrastructure sharing: An overview - future networks. [Online]. Available: https://www.gsma.com/futurenetworks/wiki/infrastructuresharing-an-overview/

[77] M. Singhal and T. Prasanna, "Developing information technology solutions in indian languages: Pros and cons," INFLIBNET Centre, 2003.

[78] S. Nougarahiya, G. Shetty, and D. Mandloi, "A review of e-commerce in india: The past, present, and the future," Research Review International Journal of Multidisciplinary, vol. 6, no. 03, pp. 12-22, 2021.

[79] H. H. H. Mahmoud and et al., "6g: A comprehensive survey on technologies, applications, challenges, and research problems," Transactions on Emerging Telecommunications Technologies, vol. 32, no. 4, p. e4233, 2021.

[80] E. J. Oughton and et al., "Assessing the capacity, coverage and cost of 5G infrastructure strategies: Analysis of the Netherlands," Telematics and Informatics, vol. 37, pp. 50-69, 2019.

[81] E. J. Oughton and et al, "An open-source techno-economic assessment framework for 5G deployment," IEEE Access, vol. 7, pp. 155930 $155940,2019$.

[82] O. Kodheli and et al., "Satellite communications in the new space era: A survey and future challenges," IEEE Communications Surveys Tutorials, vol. 23, no. 1, pp. 70-109, 2021.

[83] Y. Henri, "The OneWeb satellite system," Handbook of Small Satellites: Technology, Design, Manufacture, Applications, Economics and Regulation, pp. 1-10, 2020.

[84] T. Han and et al., "Emerging drone trends for blockchain-based 5G networks: Open issues and future perspectives," IEEE Network, vol. 35, no. 1, pp. 38-43, 2021.

[85] Loon: Expanding internet connectivity with stratospheric balloons. [Online]. Available: https://x.company/projects/loon/

[86] S. Aust and et al., "Outdoor long-range WLANs: A lesson for ieee 802.11ah,” IEEE Communications Surveys Tutorials, vol. 17, no. 3, pp. $1761-1775,2015$

[87] P. Burugadda and et al., "Development of budget friendly wireless access point to use in littoral environments," in International Conference on Wireless Communications Signal Processing and Networking (WiSPNET), 2020, pp. 164-167.

[88] K. Ab-Hamid and et al., "Self-sustainable energy efficient long range WiFi network for rural communities," in GLOBECOM Workshops, 2011, pp. 1050-1055.

[89] A. Thakur and C. Hota, "Sustainable wireless internet connectivity for rural areas," in International Conference on Advances in Computing, Communications and Informatics (ICACCI), 2013, pp. 1335-1340.

[90] V. S. Anusha and et al., "Comparative analysis of wireless technology options for rural connectivity," in 7th International Advance Computing Conference, 2017, pp. 402-407.

[91] A. Pentland and et al., "DakNet: rethinking connectivity in developing nations," Computer, vol. 37, no. 1, pp. 78-83, 2004.

[92] "ERNET annual report 2015-16." [Online]. Available: https://ernet.in//sites/default/files/pdf/English_2015-16.pdf/

[93] ERNET. [Online]. Available: https://ernet.in/projects/fsoc.html 